\title{
Deterritorialización y ciudadanización de los Guaymí
}

\section{Deterritorialization and citizenship of the Guaymí}

\author{
Ana Sofía Solano-Acuña ${ }^{1}$ \\ Universidad Nacional, Costa Rica
}

\begin{abstract}
Resumen
Esta es una experiencia donde se unen la geografía, la antropología y la historia con el objetivo de revelar la identidad insurgente y anticolonial del occidente de Panamá, particularmente del pueblo guaymí. Tras la historia nacional es necesario descubrir la historia regional y la historia étnica en particular, ambas absorbidas por discursos homogeneizantes y totalizadores donde la polifonía de las voces disidentes ha sido borrada. Desde finales del siglo XIX e inicios del XX la idea de "espacio vacío" convivió y compitió con la de "espacio salvaje", lo cual es posible rastrear en prensa, documentación oficial y escritos de intelectuales. En esta entrega quiero hacer un recorrido por las estrategias (políticas, económicas e ideológicas) del Estado y las élites para desgarrar el etnoterritorio y administrar a la población indígena y sus bienes en el marco de un Estado Nacional en consolidación y de una identidad nacional excluyente en proceso de construcción.
\end{abstract}

Palabras clave: Territorios culturales-etnoterritorios-guaymí-ciudadanización-desterritorialización.

\begin{abstract}
This is an experience where geography, anthropology and history come together in order to reveal the insurgent and anti-colonial identity of western Panama, particularly of the Guaymí people. After national history it is necessary to discover regional history and ethnic history in particular, both absorbed by homogenizing and totalizing discourses where the polyphony of dissenting voices has been erased. From the late nineteenth and early twentieth centuries the idea of "empty space" coexisted and competed with that of "wild space", which is possible to trace in the press, official documentation and writings of intellectuals. In this issue I want to take a tour of the strategies (political,

1 Candidata a Doctora por el programa de Historia y Estudios Humanísticos de la Universidad Pablo de Olavide (UPO), España. Académica, Facultad de Ciencias Sociales, Universidad Nacional (UNA), Costa Rica. ORCID: http://orcid.org/0000-0001-5189-4735.Correo electrónico: ana.solano.acuna@una.cr
\end{abstract}

Este artículo corresponde a la ponencia presentada en el 35th Conference of Latin American Geographers realizada en San José, Costa Rica del 20 al 22 de mayo del 2018. 
economic and ideological) of the State and the elites to tear down the ethnoterritory and administer the indigenous population and its assets in the framework of a National State in consolidation and an exclusive national identity in the process of construction.

Keyword: Cultural territories-ethnoterritories-guaymí-citizenship-deterritorialization.

\section{Introducción}

Los territorios culturales se comprenden como los espacios históricos e identitarios reconocidos como propios por cada pueblo o sociedad, pues en él no sólo encuentra habitación, sustento y reproducción sino también oportunidad de transmitir prácticas socioculturales a través del tiempo (Barabas, A. 2008). El control e identificación territorial tiene implicaciones directas sobre los procesos de construcción étnica pues amarra un presente indígena con un pasado, con los ancestros, con la génesis misma de un pueblo.

Comprenderé como etnoterritorios aquellos habitados por los grupos etnolingüísticos quienes, en su tradición oral, los comprenden y los asumen como propios. La imaginación geográfica a través de la ubicación de asentamientos, la interconexión de los mismos en su vida cultural, la narración de recorridos migratorios, la historización de los procesos de conformación de comunidades, así como la "imaginación del territorio ancestral" revela el espacio como fundamental en los procesos identitarios de los guaymí.

Una de las características de un espacio significado es su condición de "centro cósmico", vital para el grupo que lo imagina y lo ha dotado de sentidos y poderes terapéuticos, mágicos, y de afectividad y confianza (Barabas, A. 2008). Para Fernando Santos-Granero (2005) la importancia de articular la idea de territorio para las sociedades indígenas mediante sus relatos y recuerdos, no tiene como valor máximo la fidelidad de dicho relato, sino la capacidad de convertirse en una parte integral de la conciencia histórica y de la identidad. Desde esta lógica, el mecanismo del recuerdo toma especial relevancia cuando el territorio del que se habla ha sido expoliado, en ese caso el relato se convierte en resistencia.

La interacción social con las entidades territoriales en cada encuentro cotidiano o ritual, si bien es singular en cada ocasión, va creando un fondo de sedimentación de representaciones permitiendo a la colectividad elaborar un imaginario social más o menos compartido acerca de las características y fisonomía de esas entidades sagradas (Barabas, A. 2008). 
Miguel Bartolomé (2010) propone que el territorio étnico no es delimitado pero tampoco es indefinido; incluye espacios diversos pero no se restringe a estos, pues se pueden encontrar y reproducir en otros ámbitos, así como apropiarse física y simbólicamente de estos. Este característica es de vital trascendencia para el caso de los guaymí contemporáneos pues se han ido desplazando de su territorio histórico, el cual nunca deja de ser importante en su proceso identitario, pero se apropian y resignifican nuevos espacios.

Este trabajo es parte de mi investigación doctoral "Imágenes de la memoria y el poder: Los guaymi del occidente de Panamá en la conformación del Estado Nacional (1880-1925)" la cual estoy desarrollando bajo la supervisión del Dr. George Lovell en el programa de Historia y Estudios Humanísticos de la Universidad Pablo de Olavide (UPO-España). En esta ponencia me centraré en exponer la articulación territorial que el mundo guaymí pudo tener en el periodo de 1880-1925, misma que rescato de la documentación oficial, documentos emitidos por civiles y dirigentes indígenas, viajeros, intelectuales, científicos y prensa de la época. La documentación primaria que sustenta este trabajo se encuentra dispersa en cuatro países (España, Costa Rica, Panamá y Colombia), en cuanto al trabajo etnográfico se llevo a cabo en Panamá y Costa Rica.

Para el trabajo de archivo y etnográfico he contado con una beca de estudios e investigación por parte de la Universidad Nacional (UNA-Costa Rica), en el marco de su Plan de Fortalecimiento para el Sector Académico. De igual manera he recibido apoyo del Smithsonian Tropical Research Institute (STRI-Panamá) a través de una pasantía de investigación bajo la tutoría del Dr. Fernando Santos Granero. Complementario esto, ha sido de vital importancia el sustento brindado por el Centro de Posgrado de la Universidad Santa María La Antigua (USMA-Panamá), que a través del Dr. Carlos Fitzgerald me ha facilitado condiciones para el levantamiento de parte del trabajo etnográfico y documental en este país.

Dentro de la documentación han sido invaluables los informes de viajeros, intelectuales y científicos (Orlando Roberts (1827), Pinart (1885), W. Holmes (1887,1888), Reclus (1886, 1888), George Grant Maccurly (1913), Merritt (1856), Carl Bovallius (1881-1883), Hyatt Verrill (1919, 1922, 1924, 1926, 1927, 1928, 1932, 1943), Bayard Taylor (1854), Felipe Pérez (1862), Tomás Cipriano de Mosquera (1852,1866), M.M. Alba 
(1928), Manuel María de Peralta (1880, 1901), León Fernández (1881), William Holmes (1887), W. Bollaert (1863)) que han ofrecido detalles sobre el espacio geográfico, la situación de Panamá en términos políticos y económicos, particularidades sobre la población, economía y las relaciones interétnicas, el espacio occidental y la población indígena en relación con el poder colombiano y luego panameño.

\section{¿Quiénes son los guaymí?}

La gente guaymí de la que hablaré, encontrada entre informes de misiones, pleitos y solicitudes al Estado son los ancestros de 9.543 personas que hoy día viven en Costa Rica y de 285.033 sobrevivientes en Panamá. Y muchos más, que bajo el velo del proceso de mestizaje y de etnocidio, con dificultad a veces y con vergüenza en ocasiones, recuerdan a ese ancestro indígena.

En el caso de Panamá continúan resistiendo en Chiriquí, Bocas del Toro, Veraguas y una importante cantidad de población en la Ciudad de Panamá como migrantes laborales. En el año de 1997 luego de una larga lucha, a través de la Ley $N^{\circ} 10$, Gaceta Oficial No 23.242 se crea la Comarca Ngäbe-buglé con un área de $6968 \mathrm{~km}^{2}$. Dicha Comarca se crea a partir de territorio de Bocas del Toro, Chiriquí y Veraguas, y su cabecera es Llano Tugrí.

En Costa Rica se ubican en cinco territorios indígenas, Abrojo Montezuma (reconocida en 1980), Altos de San Antonio (reconocida en 2001) y Conte Burica (reconocida en 1982) en el cantón de Corredores, y Coto Brus (reconocida en 1981) en el cantón de ese mismo nombre y se extiende en parte sobre el de Buenos Aires. Alto Laguna de Osa (reconocida en 1993) se ubica en el cantón de Golfito y colinda con el Parque Nacional Corcovado. Al igual que en Panamá también se ubica población guaymí dispersa en otras partes del país, principalmente en aquellas zonas donde son requeridos como trabajadores temporales (cosecha de café, pisca de fruta, bananeras, entre otros) redoblando con esto su condición de vulnerabilidad social.

La conformación de estos cinco territorios guaymí en territorio costarricense es el resultado de un proceso de desplazamiento de grupos familiares, principalmente de Chiriquí, en los años cuarentas del siglo XX en búsqueda de nuevas tierras para asentarse y producir su sustento. Hasta el año de 1991 el Estado de Costa Rica mediante Ley No 7225, Ley de inscripción y cedulación 
indígena, declara la obligación del Estado de otorgar cédulas de identidad costarricense a los guaymí (Guevara Berger, M. 2000).

Esta sociedad indígena pertenece a la estirpe chibchense (Constenla Umaña, A. 1991; Hasemann, G. Lara Pinto, G y Cruz Sandoval, F. 1996), es la etnia la más populosa de toda la Baja Centroamérica, la que se encuentra en condición de mayor pobreza y posee en ambos países indicadores que hablan de una alta marginalidad con respecto a otros pueblos indígenas y a la población mestiza.

Al interno del mundo guaymí se muestras diferencias, principalmente lingüísticas pues existen dos lenguas vivas perfectamente identificables, el ngäbere y el buglére. La primera según Juan Diego Quesada (2012) es la lengua de la familia chibcha que posee el mayor número de hablantes, aproximadamente 150.000. En el presente etnográfico, se pueden ubicar uniones matrimoniales entre personas que hablan lenguas diferentes y se desarrollan ambientes bilingües o poliglotismos familiares al interno del mundo guaymí.

En las fuentes trabajadas para esta investigación, es decir, las que abarcan el periodo de 1880-1925 aproximadamente, los de habla buglére también pueden encontrarse como bobota, bocota, bofota, bogota, bokota, bukueta, murire, norteño, veraguas sabanero o sabanero; los de habla ngäbere pueden localizarse como ngöbere, ngäbe, valiente o movere en las mismas fuentes.

En cuanto a la referencia del gentilicio guaymí, las primeras referencias datan del siglo XVII y fueron elaboradas por Fray Adrián de Santo Tomás producto de su convivencia entre ellos. Philip Young (1968) a través de su especial interés por los proceso de cambio y continuidad, corroboró que a pesar de más de 300 años de contacto (regular o intermitente), algunos elementos fundadores ${ }^{2}$ de la sociedad guaymí descrita por el fraile se mantenían prácticamente sin cambio. Este fenómeno es explicado por el autor en parte porque la geografía del occidente de Panamá jugo a favor de la sociedad indígena en algún sentido, retrasando o complicando el acceso del mundo occidental a las zonas altas y de más difícil acceso. La cordillera y las islas fueron los espacios de resistencia por excelencia, pues las llanuras y las costas rápidamente fueron expoliadas y desmembradas del mundo indígena.

2 Resalta el sistema de parentesco, patrón de asentamiento en caseríos dispersos, trabajo recíproco o mano vuelta, distribución del excelente, entre otros. 
Los actuales guaymíes (ngäbes y bugles) están hoy en donde estuvieron sus ancestros (al este y al oeste del río Tabasará), sufriendo de una reducción sustancial de su territorio y de un paulatino proceso de asimilación cultural (Young, P. 1968). A lo largo de su obra se ocupó de analizar los elementos que desde su perspectiva hizo y hace posible que esta sociedad indígena sobreviva hoy día, identificando una sociedad indígena vigilante del entorno y flexible al mismo en busca de reconceptualizar su identidad. Este autor identifica que en los años sesentas, los descendientes de los guaymí abandonaron en gran número el territorio histórico y se identificaron como mestizos; esta identificación es concebida como una forma de resistencia en aquel momento pero pronto rechazaron el mestizaje y volvieron a su identificación como indígena (Young, P. 2014).

Plantea que hubo un proceso de ladinización in situ de los guaymí en algunas regiones, dicho proceso a simple vista hace considerar una gradual desaparición del indígena, pero más bien emerge una identidad local pues no necesariamente hay una renuncia abierta a su origen sino se dan adaptaciones al medio; plantea además que ese parecer "mestizo" o "cholo" es parte de las estrategia de resistencia-sobrevivencia desarrollada a lo largo de los años por el pueblo guaymí.

Las sociedades indígenas del pasado como las del presente, deben ser abordadas como colectivos vivos que modelan su vida de acuerdo a situaciones internas y externas, no son homogéneas, ni permanecen congeladas en el tiempo, en ocasiones pueden presentar incongruencias o contradicciones como cualquier sociedad humana, pero cuyo fin supremo siempre es sobrevivir y adaptarse.

\section{Área de estudio y la temporalidad}

En la presente investigación tengo como punto de partida la necesidad de reconstruir en la medida de las posibilidades el mundo indígena del periodo de 1880-1925, y eso incluye como primera tarea reconocerlo espacialmente. Para esta definición espacial he escuchado con espacial atención las advertencias que por años y a través de varios escritos hicieran Richard Cooke (1982) y Olga Linares (1970) principalmente, quienes desde sus investigaciones y reflexiones se interrogaron sobre la continuidad y la ruptura entre el pasado precolombino y el presente etnográfico en el occidente de Panamá. 
El territorio nacional, para el periodo investigado, interesa por su contenido y su grado de coherencia interna, su espacio se concibe como un producto social, por lo tanto, histórico. La documentación testimonia un imaginario deshistorizador del territorio, es decir, desde las interpretaciones, apreciaciones, descripciones se sugiere que el oeste del país no poseía una historia cultural y por el contrario, se invitaba a construirla.

La idea de "espacio vacio" convive y compite con la de "espacio salvaje", es posible rastrearlos en prensa, documentación oficial y escritos de intelectuales. Es así como, tras la historia nacional, es necesario develar la historia regional occidental y la historia étnica en particular, ambas decoloradas por discursos homogeneizantes y totalizadores donde la polifonía de las voces disidentes es borrada. Tal como lo propone Arturo Taracena Arriola (1999), a través de la historia de una región podemos comprender no solo un fenómeno histórico local, sino que nos proporciona herramientas para analizar la construcción del Estado nacional y para entender el presente de proyectos nacionales en crisis.

El punto de partida para los historiadores y antropólogos consistente en el análisis del espacio y el tiempo desde la actividad social producida por los seres humanos que los habitan y hacen posibles. Tal actividad se traduce en actos identitarios, procesos económicos y políticos, en palabras sencillas la región en sí es una construcción social en la historia y no un determinismo de origen geográfico o administrativo (Taracena Arriola. 2008).

Existen muchas posibilidades para definir la región occidental de Panamá, desde dentro o desde fuera. Esto en parte a su ubicación estratégica y a las interacciones sociales y culturales que en ella se han dado. Pero cabe destacar, el occidente tanto en el pasado como en el presente no es solamente un punto de unión entre Centroamérica y Panamá, sino más bien un espacio donde se reconfiguran identidades de todo tipo, una de las más importantes la étnica.

Gerhard Sandner (1981) plantea, en el caso de Panamá después del "goldrush" y del poblamiento de California posterior a 1848, el istmo se convirtió en un espacio de tránsito "intra americano" y en una grieta-conexión entre México/Centroamérica y Suramérica. Para el siglo XIX hay una política de penetración del istmo centroamericano de parte de potencias lejanas, particularmente de los Estados Unidos. Como veremos a lo largo del periodo de estudio, dicha penetración podría ser pensada de amplio 
espectro con respecto a la suerte de las sociedades indígenas, por el contrario, es un elemento definitorio en lo económico, lo político y hasta lo simbólico identitario. Zonas consideradas en el pasado como periféricas del poder español y del control republicano, en los primeros años del siglo XX, van a convertirse en nuevos espacios de extracción de riquezas, conllevando con ello nuevas formas de explotación y de relación con las poblaciones que en ellas habitaban. En este contexto se acelera el expolio territorial de sectores rurales e indígenas, no solo en Panamá sino en todo istmo centroamericano.

La importancia del istmo de Panamá dentro de este escenario, justificó el organizar todo dentro y fuera para "blindar" los intereses extranjeros. En Panamá, el encuentro entre la estructura colonial heredada en la economía y la economía global orientada hacia el capital a finales del siglo XIX, transformó la organización del trabajo, la economía de subsistencia, irrumpió en las organizaciones de tipo étnico-territorial, en los procesos de identidad y reconocimiento político étnico, en la legislación nacional, solo por citar algunos impactos. Se entró además a una revaloración del espacio nacional, primero colombiano y luego panameño, donde los espacios de poco valor empezaron a ser requeridos con cierta urgencia como parte de proyectos nacionales con raíces en la economía extranjera. Parte de la necesidad de incorporar esta parte del territorio también se dio por la trayectoria de iniciativas separatistas de las que podemos tener testimonio en la documentación de esta época, así como los yacimientos de carbón y las minas de oro.

Para poder ser coherente en la construcción de historiografía sobre sociedades indígenas, es necesario además y previo a ello, identificar espacialmente desde las mismas voces indias como se hilo ese mundo y como se materializó espacialmente.

Cabe mencionar que en un lapso de cuarenta y cinco años que es lo que abarca esta investigación, la territorialidad guaymí varió conforme sucedieron acontecimientos internos y externos que la fueron impactando. Hacia finales del siglo XIX la documentación relata una territorialidad amplia, robusta, fuerte y hasta cierto punto peligrosa, que incluía lugares remotos como Bocas del Toro, Punta Burica, La Pintada y Coclé, y básicamente todos los pueblos ubicados sobre lo que años más tarde será la Carretera Interamericana. 
Para principios del siglo XX se puede identificar una disminución importante en términos territoriales, quizás me permito indicar que muy acelerada para el lapso de tiempo que transcurrió. Una fecha importante que va a dar un giro no solo al volumen de documentación, sino a la calidad de la misma y al abordaje político-conceptual de esta población será el proceso de independencia de Colombia, el 3 de noviembre de 1903. A partir de esta fecha se pueden rastrear acciones de tipo administrativo, político e ideológico que buscarán desagregar el sector centro-occidente (Coclé, La Pintada, Penonomé) de ese interrelacionado mundo indígena y redefinirlo como "cholo" o "mestizo". La resistencia mostrada por estos poblados durante la Guerra de los mil días (1899-1902), convirtieron a esta región y su población en una prioridad de incorporación al Estado Nacional (primero colombiano y luego panameño), tanto por sus demandas políticas y económicas, como por seguridad estratégica.

Para este periodo además, se tendió a criminalizar la lucha y las demandas indígenas, y se exacerbó el tratamiento de "frontera salvaje" para referirse a sus espacios vitales donde el Estado no tuvo o poseyó presencia de forma limitada. Tal como sucedió en otras partes del continente, la perduración de las llamadas "fronteras interiores" resultaba entonces contradictoria con la idea de integridad del Estado (Roulet y Navarro, 2005). 
Mapa 1. Aproximación del pueblo guaymí a finales del siglo XIX.

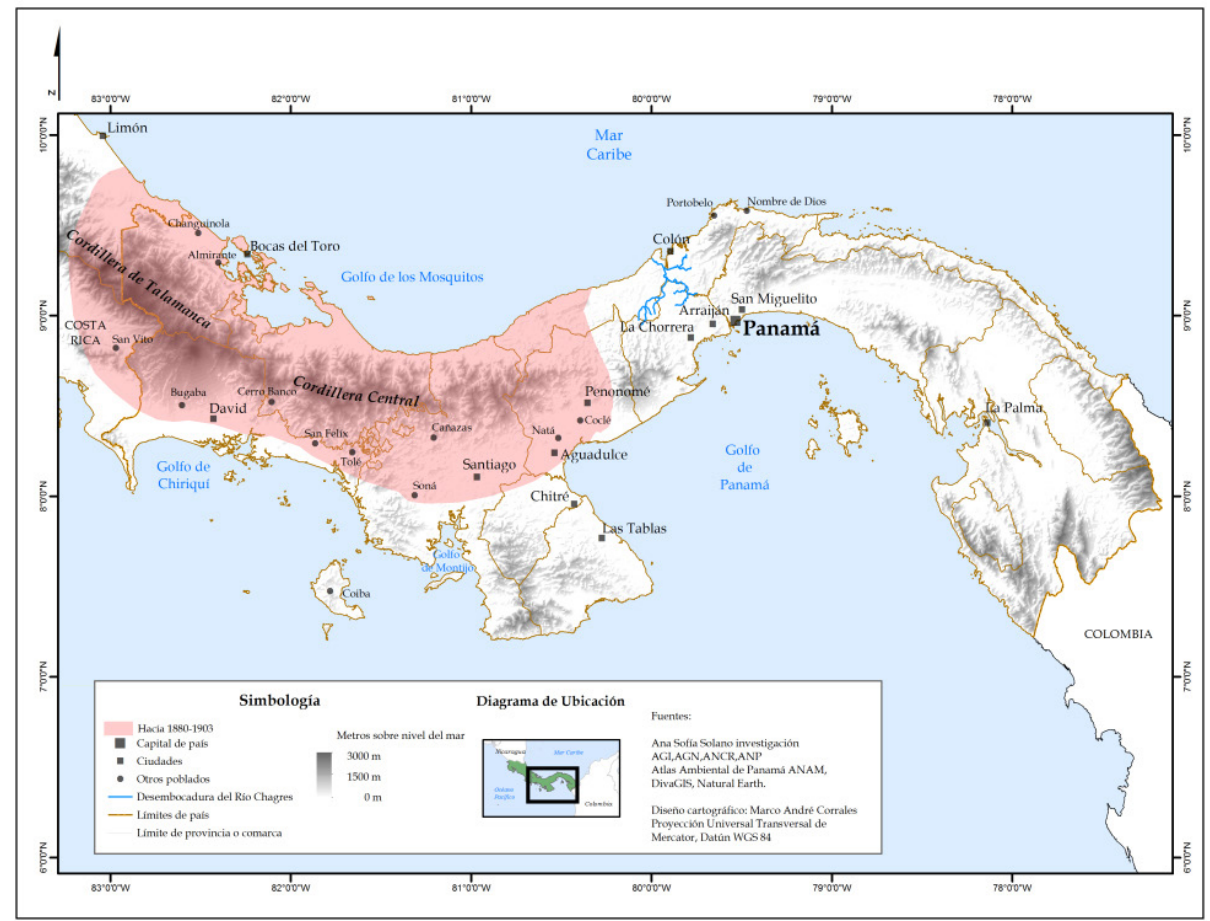

532 Revista Geográfica de América Central No 61E (3) Especial CLAG Este artículo está bajo una licencia e-ISSN 2215-2563 • Julio-diciembre 2018 • pp. 523-536 Doi: http://dx.doi.org/10.15359/rgac.61-3.27 
Mapa 2. Aproximación del pueblo guaymí a principios del siglo XX.

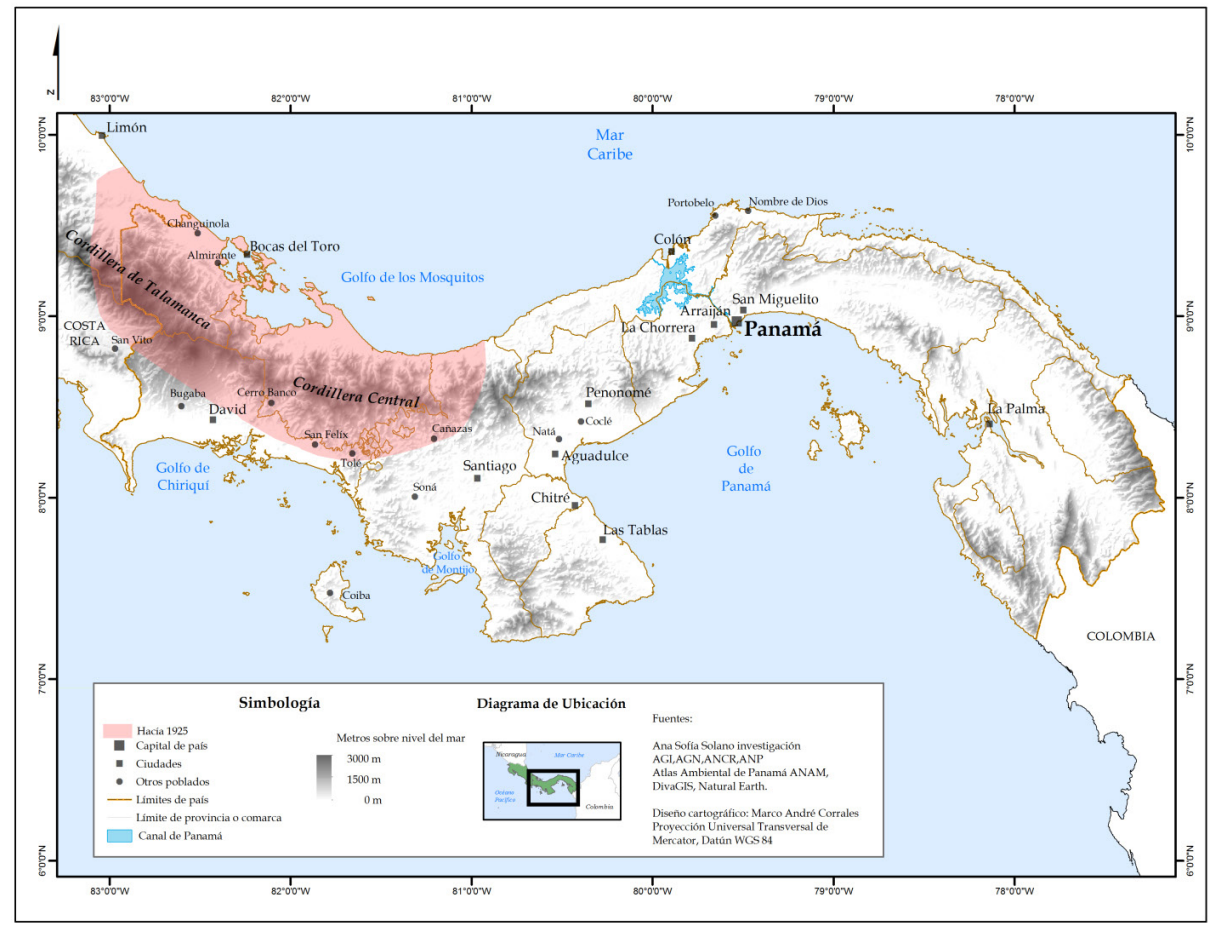

\section{Desindianiación y ciudadanización}

Tal y como lo plantean Ronald Soto y David Díaz-Arias (2007), es posible reconstruir la génesis de cómo lo indio fue incluido, excluido, invisibilizado, redimensionado y operacionalizado por los políticos e intelectuales y a su vez se puede detallar el papel que los discursos sobre el mestizaje, la desindinización y la ciudadanización jugaron en esos procesos.

En el periodo 1880 a 1925 se amalgamaron las percepciones del indígena heredadas del pasado colonial, con las ideas de raza construidas en la época y las discusiones regionales sobre el "problema indígena" y su atención.

El mecanismo de movilizar e implantar poblaciones en espacios de difícil control, despoblados o con la finalidad de impactar en las características étnicas o políticas, no es nuevo, fue una estrategia utilizada desde los tiempos de control español y retomado en el siglo XIX al calor del darwinismo social como teoría y como práctica de control poblacional. En 
la experiencia del occidente de Panamá desde principios del siglo XIX se consideró como mecanismo posible para "romper el territorio" y controlar a la población indígena, la emigración de población europea y el reasentamiento de población de origen africano como se dio en el caso de Chiriquí.

Estas prácticas buscaron no solo influir sobre el mundo indígena que hasta ese entonces había sido un fracaso en términos de su control e incorporación al proyecto nacional, sino la generación de un estrato poblacional que fuera la base de los proyectos económicos que para la fecha ya se estaban perfilando. Este último elemento hizo del campesino "cholo" un personaje mucho más vulnerable, con problemas de definición como colectivo, inexistente desde la oficialidad, sin pasado, cuyo único valor era la venta de sus brazos en las haciendas tal como lo describe Omar Jaén Suarez (1981).

La versión más conocida de esa idea le pertenece a Ronald Stutzman (1981), quien considera el mestizaje como "una ideología inclusiva de exclusión”, es decir, un sistema de ideas que parece incluir a todos como potenciales mestizos, pero en realidad excluye a los indios y negros.

Durante este periodo se constituye un mercado de tierras, es decir, hubo porciones de tierra posiblemente adecuadas a la producción para la exportación y las cuales se encontraban "inmovilizadas". Estas tierras pertenecían a órdenes religiosas, comunidades indígenas, eran tierras públicas, entre otras; todas las condiciones fueron trasgredidas para que ingresaran al mercado y se encaminarán a un proceso de privatización. En Panamá abundan los ejemplos donde se identifica las tierras como una forma de pago del Estado y una garantía para la inversión en obras públicas como el ferrocarril.

Siguiendo a Florencia Mallon (1996) el mestizaje emerge como un discurso oficial de formación de nación, un nuevo llamado a la autenticidad que niega las formas coloniales, la jerarquía racial y étnica, y la opresión a través de la creación de un sujeto intermediario como "el ciudadano". Sin embargo, el mestizaje está construido contra un "otro" indio periférico, marginalizado, deshumanizado que a menudo desaparece en el proceso. 


\section{Referencias}

Barabas, A. (2008). Cosmovisiones y etnoterritorialidad en las culturas indígenas de Oaxaca. En Antípoda. Revista de Antropología y Arquelogía, 7, 119-139.

Bartolomé, M. (2010). Interculturalidad y territorialidades confrontadas en América Latina. En RUNA, 1, 9-29.

Constenla Umaña, A. (1991). Las lenguas del área intermedia. Introducción a su estudio areal. San José: Costa Rica. Editorial UCR.

Cooke, R. (1982), “Los guaymíes si tienen historia”, El pueblo guaymí y su futuro. ¿Quién dijo que estamos cansados de ser indios?, Ciudad de Panamá: Panamá. Editorial Impretex, 26-64.

Guevara Berger, M. (2000). Perfil de los pueblos indígenas de Costa Rica. Informe final. San José: Costa Rica. Recuperado: http://pueblosindigenas.odd.ucr.ac.cr/images/documentos/pdf/Perfil\%20de $\% 20$ pueblos\%20indigenas $\% 20$ en $\% 20$ Costa\%20Rica.pdf

Hasemann, G, Lara Pinto, G y Cruz Sandoval, P. (1996). Los indios de Centroamérica. Madrid: España. MAPFRE.

Jaén Suárez, Omar. (1997).La región de los Llanos del Chirú. Un estudio de historia rural panameña. Ciudad de Panamá: Panamá. INAC.

Linares, O. (1970). Patrones de poblamiento prehispánicos comparados con los modernos en Bocas del Toro, Panamá. En Revista Hombre y cultura, 1, 56-67.

Mallon, F. (1996). Constructing mestizaje in Latin America: Authenticity, marginality and gender in the claiming of ethnic identities. En The Journal of Latin American and Caribbean Anthropology, (2)1, 171-172.

Quesada, J. (2012). Las lenguas indígenas de la Costa Rica actual. Revista WANI, 68, 19-24.

Roulet, F, Navarro Floria. (2005). De soberanos externos a rebeldes internos: la domesticación discursiva y legal de la cuestión indígena en el tránsito del siglo XVIII al XX. En Revista TEFROS, 1, 1-41.

Sandner, G. (1981). Estructuración espacio-político-geográfica y la geopolítica en la Región Caribe. En Revista geográfica de América Central, 13-14, 41-66.

Santos-Granero, F. (2005). "Writing history into the landscape: Yanesha notions of space and territoriality", The Land within: Indigenous territory and the perception of environment, Copenhagen, Dinamarca: Editorial IWGIA. 
Soto Quirós, R y Díaz-Arias, D. (2007). Mestizaje, indígenas e identidad nacional en Centroamérica: De la Colonia a las Repúblicas Liberales. San José: Costa Rica. Editorial FLACSO.

Stutzman, R. (1981). "El mestizaje: an all-inclusive ideology of exclusion". Cultural transformations and ethnicity in modern Ecuador, Illinois: Estados Unidos. Editorial Urbana.

Taracena Arriola, A. (1999). Región e historia, En Desacatos. Revista de Ciencias Sociales, 1, Recuperado: http://www.redalyc.org/articulo. oa? id $=13900104>$.

Taracena Arriola, A. (2008). Propuesta de definición histórica para región. En Estudios de historia moderna y contemporánea de México, 35, 181-204.

Young, P. (1968). The ngawbe: an analysis of the economy and social structure of the western guaymí of Panamá. Tesis doctoral. University of Illinois. Estados Unidos. (pp.471).

Young, P. (2014). "Women's Roles and Responses to Globalization in Ngäbe Communities", Mestizaje and Globalization, Transformations of Identity and Power, Arizona: Estados Unidos: The University of Arizona Press. 